\title{
Virtual water flow pattern of grain trade and its benefits in China
}

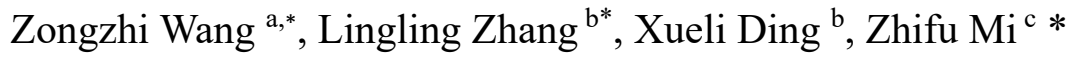

a State Key Laboratory of Hydrology-Water Resources and Hydraulic Engineering, Nanjing Hydraulic Research Institute, Nanjing 210029, China

b School of Public Administration, Hohai University, Nanjing, 210098, China

$c$ The Bartlett School of Construction and Project Management, University College London, London WC1E 7HB, UK

Abstract: Urbanization, industrialization and their associated water shortage pressures have brought great challenges to agricultural development and water security. Understanding the virtual water flow involved in the grain trade is critical to ensuring water security and agricultural production. However, there are few studies on the comprehensive benefits provided by virtual water flow in the grain trade. This paper proposes a linear optimization model to fill this gap. The model is used to estimate the virtual water flow via interregional grain trade within China in 2015 and corresponding benefits to resources, the economy, and the environment from both outflow and inflow comparative perspectives. Three results characterize the virtual water flow pattern of interprovincial grain trade in China in 2015: (1) In terms of resource benefit, 31. billion cubic meters of water resources were saved, accounting for approximately $39.7 \%$ of the total virtual water flow. (2) A positive economic benefit was realized, with an increase of 6.4 trillion yuan in industrial value added. (3) Certain regions with a high crop green water occupation index account for a considerable proportion of the green water of the local agricultural ecosystem. Simultaneously, massive output of virtual water would aggravate the destruction of terrestrial ecosystems. Finally, the results suggest that promoting the marketization of water resources, improving water productivity, exploring regional compensation mechanisms and improving green water conservation capacity should be considered for water security policies.

Keywords: Grain trade; Virtual water flow; Resource benefit; Economic benefit; Environmental benefit

\footnotetext{
* Corresponding author. Tel.: +86 25 85828506; Fax: +86 2585828555

Email addresses: wangzz77@163.com (Z.Z.Wang),1lzhang007@163.com (L.L.Zhang), z.mi@ucl.ac.uk (Z.F. Mi)
} 


\section{Introduction}

China is facing a serious water shortage as a result of the dual stresses of the decreasing availability of water resources (both in terms of quantity and quality) (Hu et al., 2010) and the ever-increasing water demand(Ercin and Hoekstra, 2014). Agriculture accounts for the greatest proportion of water use in China, responsible for $60-65 \%$ of national total blue water withdrawals (Kang et al., 2017), and as a result, water shortages are a major challenge to agricultural production ( Piao et al., 2010). Therefore, greater attention and additional measures are needed to ensure agricultural production in the case of water shortage. Grain is an important component of agricultural water consumption, accounting for $68 \%$ and $58 \%$ of crop cultivated areas and agriculture product output, respectively, in 2015 (National Bureau of Statistics, 2016). Although food demand is met primarily by production within a given region, trade with other regions also contributes. Thus, the state of interregional grain trade against the background of water scarcity should be given greater attention.

Virtual water, a term that links water, food, and trade (Allan, 2003), provides a new perspective for water shortages and water resource management (Novo and Garrido, 2009). Allan $(1993,1998)$ noted that food production involves the consumption of water resources, and virtual water is the water resources involved in the production of food and other resources, including in the grain trade. Thus, trade is a means of transferring water resources between regions. Trade in water-intensive commodities such as crops results into so-called virtual water flow between exporting and importing regions (Hoekstra, 2003). Thus, the virtual water trade is a powerful accounting tool for mapping the linkages between trade activities and human water use (Zhang and Anadon, 2014).

A growing number of virtual water trade studies have been conducted in a bid to ensure water and food security, though the methods and scales are different. At the global level, Hoekstra and Huang (2005) and Chapagain et al. (2006) calculated the volume of virtual water associated with international crop trades. The results of two studies are as follows separately : a total of $695 \times 10^{9} \mathrm{~m}^{3} / \mathrm{yr}$ of water was generated, and $352 \times 10^{9} \mathrm{~m}^{3} / \mathrm{yr}$ of water was saved through virtual water flow between nations. Konar 
et al. (2011) analyzed the structure of the global virtual water trade associated with the international food trade using a complex network method. At the national and region levels, Zeitoun et al. (2010) found that virtual water trade is important to consider in devising national water and food security policy in the Nile Basin. In addition, the amount and structure of virtual water in China's foreign trade were analyzed in many studies. Gong et al. (2007), Tao and Chen (2006) and Chen et al. (2018) found that China was a net exporter of virtual water through global foreign trade. However, the imported virtual water was larger than the exported virtual water in the trade of agricultural products between China and Trans-Pacific Partnership Agreement (TPPA) countries (Zhang et al., 2017). A paradox in the virtual water flow from north to south in China's internal grain was described (Jiang et al. 2017). At the provincial level, Zhang et al. (2011) found that Beijing imports 51\% of virtual water from other provinces. Macao greatly relies on external virtual water supplies (Chen and Li, 2015).

China has nine commodity grain bases: Sanjiang Plain, Songnen Plain, Taihu Plain, Jianghuai Area, Jianghan Plain, Poyang Lake Plain, Dongting Lake Plain, Chengdu Plain and Pearl River Delta. Sanjiang Plain and Songnen Plain are in Northeast China. Taihu Plain, Jianghuai Area, Jianghan Plain, Poyang Lake Plain and Dongting Lake Plain are in the Middle-lower Yangtze region. Chengdu Plain is in the Southwest region, and the Pearl River Delta is in South China. The grain production conditions in these areas are favorable, the proportion of farmland with high and stable yield is large, and surplus grain is abundant. As a result, the basic grain flow in China is transported from the commodity grain bases to other parts of the country.

If refined to the provincial level, according to the characteristics of production and marketing, China can be divided into major grain-producing areas, balanced areas and main selling areas. The main producing areas include the 13 provincial administrative regions of Inner Mongolia, Liaoning, Jilin, Heilongjiang, Hebei, Henan, Shandong, Anhui, Jiangsu, Hubei, Hunan, Jiangxi and Sichuan. The main 
selling areas include the 7 provincial-level administrative regions of Beijing, Tianjin, Shanghai, Zhejiang, Fujian, Guangdong and Hainan. The balance zone includes the 11 provincial administrative regions of Shanxi, Shaanxi, Gansu, Qinghai, Ningxia, Xinjiang, Guangxi, Chongqing, Guizhou, Yunnan and Tibet. Thus, the basic grain circulation in China is from the main grain-producing provinces to the main selling provinces.

The direction and quantity of grain circulation in specific provinces must be measured to analyze the state of interprovincial virtual water flow in the grain trade. There are various methods of calculating the interprovincial virtual water trade, mainly including linear programming optimization models and input-output models. A linear programming optimization model has been constructed to simulate the interprovincial food trade in China (Dalin et al. 2015). Input-output models have been composed of single-regional input-output models for Zhangye City (Wang et al. 2009) and Beijing City (Wang et al. 2013) as well as interregional input-output models (Zhang et al. 2011) and multiregional input-output models (Jiang et al. 2015). Two shortcomings of applying input-output models to the virtual water trade have been noted : One shortcoming is the general aggregation issue at the level of economic sectors rather than individual products (Weidmann etal. 2007). To be more specific, three main sectors can be recognized: the agricultural sector, industrial sector and tertiary sector. However, it is difficult to account specifically for grain according to these sectors, not to mention measuring interprovincial grain trade. The second disadvantage is that the timeliness and availability are inadequate (Miller and Blair, 2009) because the official input-output table is compiled every five years, and the latest full version is updated to only 2012. Considering the limitations of input-output models, a linear optimization model is chosen in this study. Linear programming can make up for the shortcomings of the above input-output models. The linear programming method can 
obtain detailed interprovincial trade sources and destinations of grain products using the latest data. Furthermore, linear programming is the most important method for system optimization in operational research, and it is an applied mathematical method for the rational utilization and allocation of resources.

To the best knowledge of the authors, there has been little analysis beyond conventional wisdom in the following important areas. First, previous studies mostly focused on the virtual water trade itself and failed to analyze the comprehensive benefits of virtual water trade. Most papers have recognized that virtual water trade can have positive benefits, such as water savings in cases of virtual water trade from a nation where water productivity is relatively high to another nation where water productivity is relatively low, while conversely, it generates negative effect of water inefficiency (Chapagain et al., 2005). However, the opportunity cost of associated water also must be considered in weighing the pros and cons of the virtual water trade. The water embodied in virtual water trade can also be used in economic development and environmental management. The allocation of water to serve a certain purpose (such as the agricultural sector), generally implies that other purposes (such as the economic sector and environmental requirements) are not served. Because of the problem of opportunity cost, water resources can be applied to certain uses to achieve optimal benefits. To this end, the economic and environmental benefits also must be considered. Assessing the comprehensive benefits of virtual water trade is a key approach to understanding the virtual water flow pattern as well as the impacts embodied in the grain trade in China.

Second, the calculation of the benefits of virtual water flow has been conducted mainly from the perspective of comparisons of import and export trade (Elfadel and Maroun, 2003), and the existing studies have failed to take the comparative perspective in internal trade into consideration. Due to the large population, broad land base and regional disparity in China, the internal virtual water trade and 
its comprehensive impacts can be extensive and complicated. Furthermore, the sources and destinations of virtual water flow are important in understanding the influence of each province. Thus, it is meaningful to analyze the internal virtual water trade benefit from a comparative perspective.

This paper aims not only to uncover the interprovincial virtual flow pattern embodied in the grain trade in China but also to understand the impacts on resources, the economy and the environment in terms of the virtual water flow. Based on grain production and consumption in 2015, a linear optimization model for the interprovincial grain trade under completely free circulation is constructed, in which minimizing transportation cost is the objective to estimate the virtual water flow pattern.

The paper attempts to address the following issues:

(1) What is the flow pattern and volume of China's interprovincial virtual water trade related to grain?

(2) What are the impacts of China's interprovincial virtual water flow in the grain trade on water resources, the economy and the environment?

\section{Methodology}

\subsection{Research framework}

The nexus between food and water can be expressed by virtual water, and the agricultural and food sectors are the dominant components of interregional virtual water trades (Jing et al., 2006). Many researchers have analyzed the interregional virtual water flow in the grain trade, and evaluating virtual water flow has become a key approach to understanding water scarcity and food safety(Wang et al., 2019). This paper focuses on the virtual water flow in the grain trade, combining virtual water with the grain trade; the research framework is illustrated in Figure. 1. 


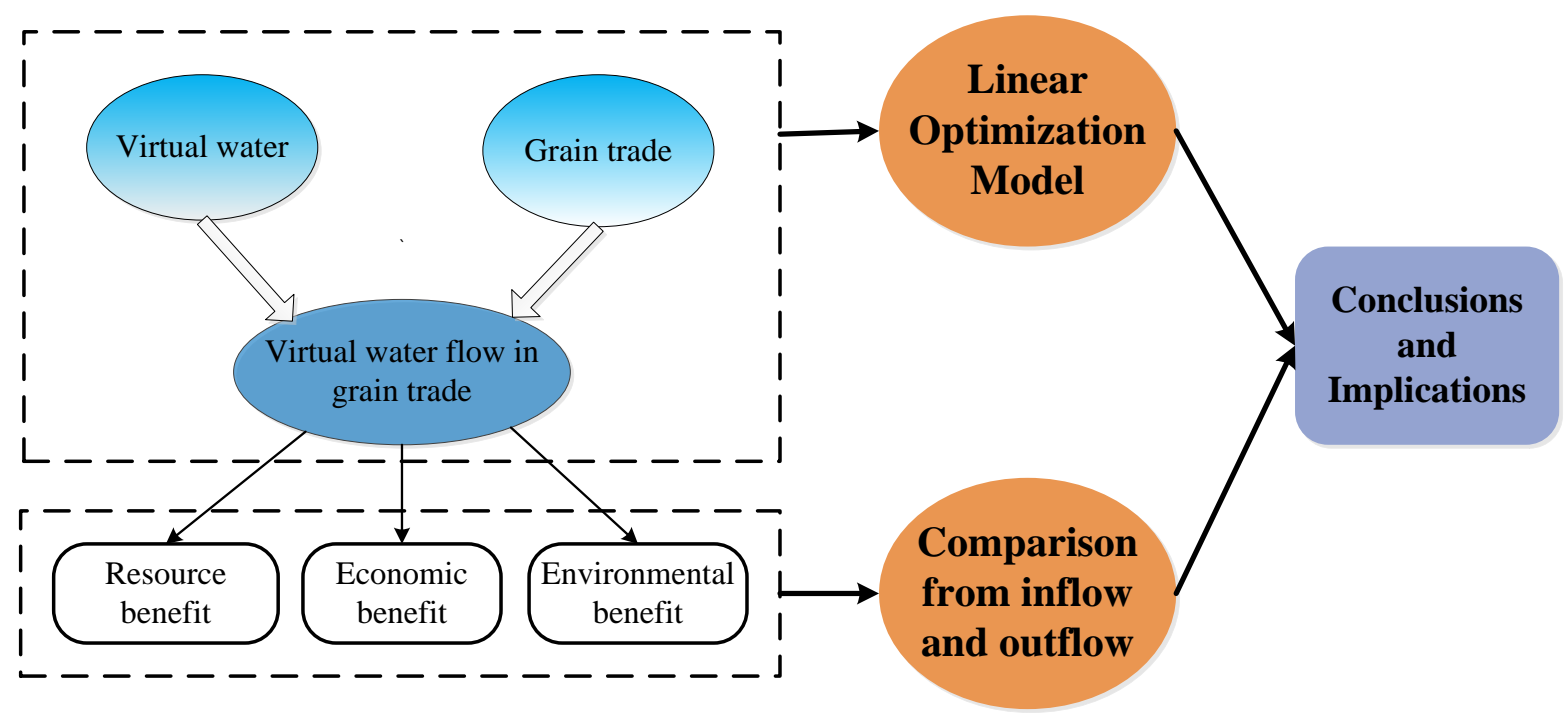

Figure. 1 Research framework of assessing the virtual water flow and benefits

\subsection{Optimization model for the regional grain trade}

In 2015, China's grain output was greater than the total amount of national grain consumption, and domestic grain could meet China's overall grain demand (Jiao et al., 2018). Considering the interprovincial trade in grain, the import and export trade of grain can be excluded. The trade flow between provinces is simulated by a linear programming model in mainland China, excluding Hong Kong, Macao and Taiwan. The model is based on the following assumptions:

(1) No change in imported and exported grain over the year; as a result, the research scope is the grain traded between provinces in China instead of import and export trade (Cheng Y. F., 2004). This assumption is mainly reflected in the processing of interprovincial grain trade data. Grain output is deducted from exports, while grain consumption is deducted from imports.

(2) The market is perfectly competitive and fully circular, leading to the consideration of grain as a homogenous product. There will be grain trade from region A to region B if the price difference between these two regions is large enough to cover the transportation cost. This assumption is mainly reflected in the determination of an objective function of the model, that is to say, minimizing transportation cost as a model objective function. (3) Grain-deficit provinces primarily receive grain from grain-surplus provinces (Zhuo et al., 2016). 
The interregional linear programming model of the grain trade is as follows.

$$
\begin{gathered}
Z=\min \sum_{i=1}^{N s} \sum_{j=1}^{N-N s} x_{i j} \times c_{i j} \\
\text { s.t. }\left\{\begin{array}{c}
c_{i j}=f \times d_{i j} \\
\sum_{j=1}^{N-N s} x_{i j}=G I Q_{i} \\
\sum_{i=1}^{N s} x_{i j} \leq G O Q_{j} \\
G I Q_{i}, G O Q_{j}, x_{i j}, c_{i j} \geq 0
\end{array}\right.
\end{gathered}
$$

where $\mathrm{Z}$ is the total transportation cost of the interprovincial grain trade, taking transportation cost minimization as the objective function; $\mathrm{x}_{i j}$ denotes the amount of transportation of grain from province $j$ to province $i ; i$ is a grain-deficit province; $j$ is a grain-surplus province; $N s$ is the total number of grain-poor provinces; $N-N s$ is the total number of grain-surplus provinces; $c_{i j}$ is the transportation cost from province $j$ to province $i$; $f$ is the grain transportation cost per unit per distance length; $d_{i j}$ is the transport distance from province $j$ to province $i ; G I Q_{i}$ is the grain deficit of province $i$; and $G O Q_{\mathrm{j}}$ is the grain surplus of province $j$. The third equation, $\sum_{j=1}^{N-N_{S}} x_{i j}=G I Q_{i}$, is the inflow constraint from the other provinces to the province in question, which is equal to an insufficient amount for that province to meet the grain demand. The fourth equation, $\sum_{i=1}^{N_{S}} x_{i j} \leq G O Q_{j}$, indicates the outflow constraint from the province in question to other provinces, which is less than or equal to the surplus of that province, ensuring grain supply in the grain surplus provinces within the scope of their own grain supply capacity. The last equation expresses that all these variables are positive.

\subsection{Virtual water flow in the regional grain trade}

Based on the above interprovincial flow of the grain trade that combines the virtual water content of grain of each region, the virtual water flow involved in the interprovincial grain trade is calculated 
easily, and the calculation is expressed as Equation (2):

$$
X_{i j}=x_{i j} \times V w_{j}
$$

in which $X_{i j}$ is the quantity of virtual water flow caused by the grain trade from province $j$ to province $i, x_{i j}$ is the grain quantity shipped from province $j$ to province $i$, and $V w_{j}$ is the virtual water content per unit of grain of outflow province $j$.

\subsection{Benefits of resource, economy and environment}

\section{(1) Resource benefit}

The resource benefit implies that water savings occurs when virtual water trade is from a region where water productivity is relatively high to another region where water productivity is relatively low, whereas water inefficiency occurs when the flow is from a low-productivity to a high-productivity area. Water productivity is reflected through the virtual water content of grain; that is to say, the higher the virtual water content of grain is, the lower the water productivity. The resource benefit is calculated by subtracting the virtual water content of the inflow area from the virtual water content of the outflow area, multiplied by the grain trade volume, as follows:

$$
R b_{i j}=\left(V w_{j}-V w_{i}\right) \times x_{i j}
$$

Here, $R b_{i j}$ is the water resources benefit caused by virtual water flows from province $j$ to province $i, i$ represents the inflow province of virtual water, and $j$ represents the outflow province of virtual water. $V w_{i}$ and $V w_{j}$ are the virtual water content of grain from inflow province $i$ and outflow province $j$, respectively. $x_{i j}$ is the grain quantity shipped from province $j$ to province $i$.

\section{(2) Economic benefit}

The economic benefit is the economic use of the water embodied in grain trade considering the opportunity cost of water. In general, industrial water has a higher economic value than agricultural water (Wang et al., 2010); thus, economic benefit is measured by the industrial added value. The increase in economic benefit occurs when virtual water is traded from a region where industrial added 
value is relatively high to another region where industrial added value is relatively low, while a negative economic effect arises when the flow is in the opposite direction. The industrial added value is calculated by dividing the virtual water quantity by the water use of industrial added value per ten thousand yuan. The industrial added value of virtual water is obtained by comparing the industrial added value between the outflow area and the inflow area.

$$
E b_{i j}=\frac{X_{i j}}{I w_{j}}-\frac{X_{i j}}{I w_{i}}
$$

where $E b_{i j}$ is the economic benefit caused by virtual water flows from province $j$ to province $i ; X_{i j}$ is the quantity of virtual water flow from province $j$ to province $i$; and $I w_{i}$ and $I w_{j}$ are the water use of industrial added value per ten thousand yuan from inflow province $i$ and outflow province $j$, respectively.

\section{(3) Environmental benefit}

Taking environmental water requirements into consideration, the environmental benefit shows the impact of virtual water embodied in grain trade on terrestrial ecosystems. This benefit is analyzed by using the crop green water occupation index proposed by Sun et al. (2010). Green water is water that has infiltrated into the unsaturated soil layer by precipitation for the growth of plants. Green water is invisible water that moves vertically into the atmosphere and can be considered to be evapotranspiration. The green water system includes water consumption of forest, grassland, wetland and rain-fed crops. It supports not only terrestrial ecosystems but also rain-fed crop production. There is a competition for green water resources between agro-ecosystems and terrestrial ecosystems. Thus, it is particularly important maintain terrestrial ecosystem security and rain-fed agricultural food security. The crop green water occupation index is the tool used to estimate the proportion of green water in agricultural ecosystems.

The green water occupation index of crops is the proportion of green water consumed in the process of crop production. The higher the green water occupation index of crops is, the higher the proportion 
of green water occupied by agro-ecosystems is, reducing the green water available to terrestrial ecosystems. The green water occupation index of crops is calculated using Equation (5):

$$
\beta=\frac{W_{\mathrm{v}}-W_{\text {irrigation }} \times \eta}{P-W} \times 100 \%
$$

where $\beta$ is the crop green water occupation index, in which "crop" refers to grain crops in this paper; $W_{v}$ and $W_{\text {irrigation }}$ are the total amount of virtual water for crop production and the irrigation water for farmland, respectively; $\eta$ is the irrigation water use coefficient in a province; and $P$ and $W$ are the total precipitation and the total amount of water resources in a province, respectively.

\section{Data collection and processing}

\subsection{Grain supply and demand}

The grain mainly consists of rice, wheat, maize, beans and potato in this paper, of which the statistical reliability is consistent with that of the statistical yearbook. The data on grain supply were obtained directly from "China Agriculture Yearbook" (Ministry of Agriculture People's Republic of China, 2016). The data on grain demand is divided into five categories based on existing research: ration consumption, feed consumption, industrial consumption, seed consumption and grain loss. Per capita grain consumption and the requirements of the resident population upon which the calculation of ration consumption is based were from the "China Statistical Yearbook" (National Bureau of Statistics, 2016). The ration consumption includes the household and outside consumption of families. The specific calculation methods are as follows: Household food consumption is calculated by per capita grain consumption multiplied by the resident population. The outside consumption of the family is measured by two categories: rural and town; $4 \%$ of household consumption is in rural areas, and $12 \%$ is in cities and towns. The data of conversion ratio (see Table 1) needed for the calculation of feed consumption were from Yang (2009). The outputs of livestock and fish were from the "China Statistical Yearbook" (National Bureau of Statistics, 2016). Feed consumption is calculated by multiplying the output of livestock and fish by their associated conversion ratios. The conversion ratio (see Table 1) 
and the output of alcohol, liquor, beer, and monosodium glutamate needed for the calculation of industrial consumption were from Yang (2009) and the "China Food Industry Yearbook" (China Food Industry Association, 2015). One part of industrial consumption is calculated by multiplying the output of these industrial products by their associated conversion ratio. Another part of industrial consumption for other uses represents $25 \%$ of the first part. Crop planting areas and the seed consumption per unit area needed for the calculation of seed consumption were from the "China Agriculture Yearbook" (Ministry of Agriculture People's Republic of China, 2016) and Yang (2009), respectively. Seed consumption is calculated by various crop planting areas multiplied by the seed consumption per unit area, and the seed consumption per unit is as follows: rice is $75 \mathrm{~kg} / \mathrm{ha}$, corn is $75 \mathrm{~kg} / \mathrm{ha}$, soybean is 75 $\mathrm{kg} / \mathrm{ha}$, and other grain use is $225 \mathrm{~kg} / \mathrm{ha}$. Grain loss includes inventory loss, transportation loss and processing loss, and inventory loss is calculated by $2 \%$ of grain production, Transport and processing losses are calculated as 4\%o and 5\%, respectively, of the sum of ration consumption, feed consumption, and industrial consumption. Details of data processing can be found in Table 2 .

Table 1 Ratio conversions used by grain consumption calculation

\begin{tabular}{llllll}
\hline Feed & Pork & Beef and mutton & Poultry & Eggs & Fish \\
\cline { 2 - 6 } consumption & $1: 4$ & $1: 2$ & $1: 2$ & $1: 2.5$ & $1: 1$ \\
Industrial & Alcohol & White wine & Beer & Monosodium glutamate & \\
consumption & $1: 3$ & $1: 2.3$ & $1: 0.172$ & $1: 2.4$ & \\
\hline
\end{tabular}

Table 2 Overview of data processing

Data type Processing method

Grain supply:

Grain yield Obtained directly

Grain demand:

Ration consumption Included household and outside consumption 
Feed consumption

Industrial consumption

Seed consumption

Grain loss
Calculated by the feed conversion rate

Calculated by the conversion ratio

Calculated by the crop planting area multiplied by the seed consumption per unit area

Included inventory loss, transportation loss and processing loss

\subsection{Grain circulation}

The circulation of China's interprovincial grain occurs mainly by railway (Ben et al. 2016). The cost of grain transportation is the cost of rail grain transport, and the distance of transport was based on the odometer readings between the main railway stations of the national railway. The transportation distance of certain provinces is replaced by the shortest mileage of the provincial capital city station in the national mileage information of the railway stations. The average cost of national grain transport per mile is obtained by railway freight information.

\subsection{Virtual water in the grain trade}

The virtual water content of grain for each region should be of the utmost importance. The virtual water content of crops in every province in China is calculated by the following steps according to data for 2015 (What we used is the China Meteorological Forcing Dataset developed by the Data Assimilation and Modeling Center for Tibetan Multi-spheres, Institute of Tibetan Plateau Research, Chinese Academy of Sciences. The dataset can be obtained from the website ftp://210.72.14.134/Data/DAT-31.0002.02.16.NG_ITPCAS-CMFD_B_v1.6/._ More～detailed information about the dataset can be seen in the user's guide for the dataset (http://dam.itpcas.ac.cn/data/User_Guide_for_China_Meteorological_Forcing_Dataset.htm). First, this study adopts a commonly used formula for calculating the virtual water content of crop products at home and abroad. The virtual water content per unit of grain is calculated from crop water 
requirement $\left(\mathrm{m}^{3} / \mathrm{ha}\right)$ divided by crop yield $(1000 \mathrm{~kg} / \mathrm{ha})$. Second, crop yield is obtained from the “China Statistical Yearbook” (National Bureau of Statistics, 2016). Third, the crop water requirement is calculated from the accumulated crop evapotranspiration over the complete growing period. The crop evapotranspiration is calculated by multiplying the reference crop evapotranspiration by the crop coefficient. The crop evapotranspiration is calculated on the basis of the FAO Penman-Monteith equation (Allen et al., 1998). The crop coefficient is referenced from Sun and Zhang's study (Sun et al, 2009). Fourth, we aggregate the virtual water contents of several agricultural products into one, called the virtual water content of grain, which is calculated by production weights. In addition, by combining the grain trade measured above by a linear programming model with virtual water, the virtual water flow in grain trade between provinces is estimated.

\subsection{Benefits}

The resource benefit is determined by the virtual water content of grain. The economic benefit is measured by the water consumption of industrial added value per ten thousand yuan, which was from the “China Water Resources Bulletin” (Ministry of Water Resources People’s Republic of China, 2015). The environmental benefit is measured by the crop green water occupation index, which requires the quantity of irrigation water use, the irrigation water use coefficient, total precipitation and total water resources. These data were from the "China Water Resources Bulletin" (Ministry of Water Resources People's Republic of China, 2015) and the "China Statistical Yearbook” (National Bureau of Statistics, 2016), statistical yearbooks of provinces (municipalities, autonomous regions), and the rural water conservancy network in China

\section{Results and discussion}

\subsection{The flow pattern of virtual water in the grain trade}

According to the results of the proposed linear optimization model, the grain trade flow pattern among provinces in China was obtained, in which 13 regions were taken as the grain outflow areas 
and 18 regions were taken as the grain inflow areas. China's grain output is $24.9 \times 10^{9} \mathrm{~kg}$ greater than its grain consumption, indicating that interprovincial grain flow cold meet the grain demand of various regions in China under the condition of full circulation in 2015. As a result, self-sufficiency in grain and the food security of China were ensured. The virtual water flow embodied in the grain trade is obtained by the grain trade flow multiplied by the virtual water content of grain (see Figure. 2).

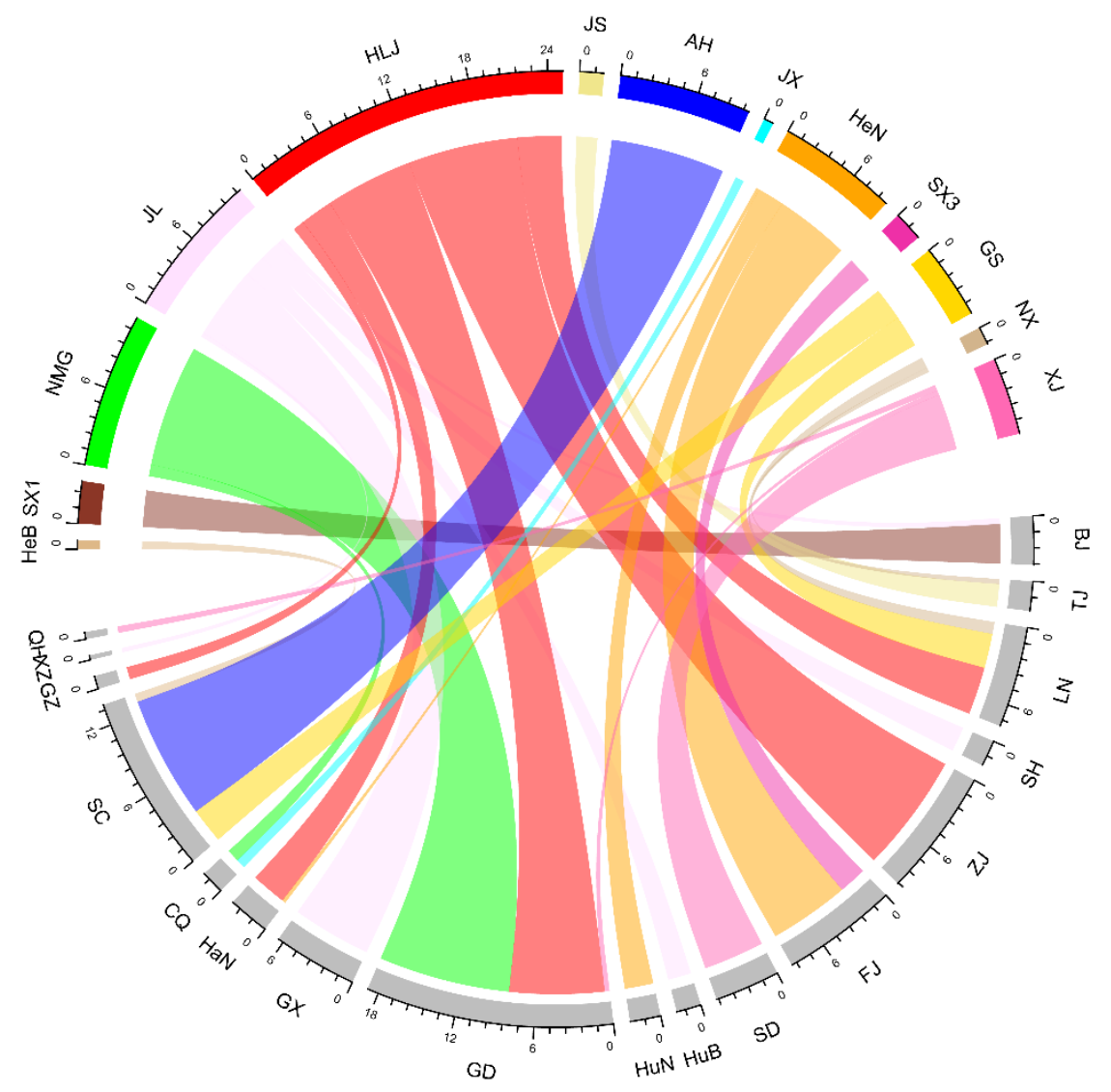

Figure. 2 Virtual water flow pattern of the interprovincial grain trade in China under full circulation

Notes: Abbreviations are for the provinces of China, excluding Hong Kong, Macao and Taiwan, and more details are provided in Appendix A.

In general, the total virtual water flow of the interprovincial grain trade in China is $79.2 \times 10^{9} \mathrm{~m}^{3}$, accounting for $2.8 \%$ of the country's total yearly water resources and $20.5 \%$ of the total agricultural water consumption. For the regional dimension, the virtual water flow pattern in China's interprovincial grain shows the characteristics of water being transferred from the north to the south, 
which is similar to the pattern observed in a previous study (Cao et al., 2011). There exists a contradiction between the virtual water flow and real water distribution, which to a certain extent intensifies the water shortage in northern China.

The authors obtained different performances of virtual water flow from the perspective of inflow and outflow areas. In terms of outflow area, Heilongjiang is the region with the largest volume of virtual water outflow, of which the outflow is $21.6 \times 10^{9} \mathrm{~m}^{3}$, flowing to Liaoning, Zhejiang, Guangdong, Hainan and Guizhou. Hebei is the region with the lowest outflow of virtual water, of which the outflow is $0.6 \times 10^{9} \mathrm{~m}^{3}$, flowing only to Sichuan. The volume of virtual water outflow is mainly from Heilongjiang, Jilin and Inner Mongolia, which account for 53.5\% of the total volume of virtual outflow. We attribute the phenomenon of the massive outflow of virtual water to the following factors: Heilongjiang was the highest ranking grain output region in 2015 , accounting for $63.2 \times 10^{9} \mathrm{~kg}$ (excluding grain exports). Jilin and Inner Mongolia were both grain surplus areas, where production is larger than consumption.

In terms of inflow areas, Guangdong is the region with the largest volume of virtual water inflow, at $16.3 \times 10^{9} \mathrm{~m}^{3}$, from Inner Mongolia, Heilongjiang and Xinjiang. Tibet is the area with the minimum virtual water inflow, all from Jilin. The virtual water inflow is mainly from Guangdong, Sichuan and Zhejiang, accounting for $46.2 \%$ of the total virtual water flow. We have classified the reasons for the inflow into economy and population as follows: the economic development of Guangdong and Zhejiang is crowding out agricultural production, while population increases lead to a huge demand for grain consumption. Although Sichuan is a granary province, its large population has resulted in a grain deficit.

\subsection{Benefit analysis}

Based on the virtual water flow of China's interprovincial grain trade, this research analyzed the resource, economic and environmental benefits caused by virtual water flow from an inflow and outflow comparative perspective. 


\section{(1) Resource benefit: water saving or water inefficiency}

The water resource is transferred from water-scarce regions to water-abundant regions, representing an irrational utilization of water resources from the total volume perspective. This overall situation is determined by the difference of resource endowment between the North and the South. This difference includes not only water resources but also arable land resources. Many studies find the arable land resources have obvious advantages in grain production. In this paper, we focus on the water resource, not arable land or other resources needed for grain production. Trade can be an instrument to allocate and use the national water resource. The resource benefit of virtual water flow is analyzed by comparing virtual water content of grain between trading partners. Virtual water content of grain represents water productivity, and the higher the virtual water content of grain is, the lower the water productivity is. Thus, water saving or water inefficiency occurs due to the different virtual water contents of grain.

The calculation results show that the virtual water flow in China's interprovincial grain trade plays a role in water saving on a national scale, as shown in Table 3 . The volume of water savings is $31.4 \times 10^{9}$ $\mathrm{m}^{3}$, accounting for $8.2 \%$ of the national agriculture water consumption. The positive benefit of virtual water trade occurs mainly because the virtual water typically flows from regions with low virtual water content of grain to regions with high virtual water content, as shown in Figure. 3. 


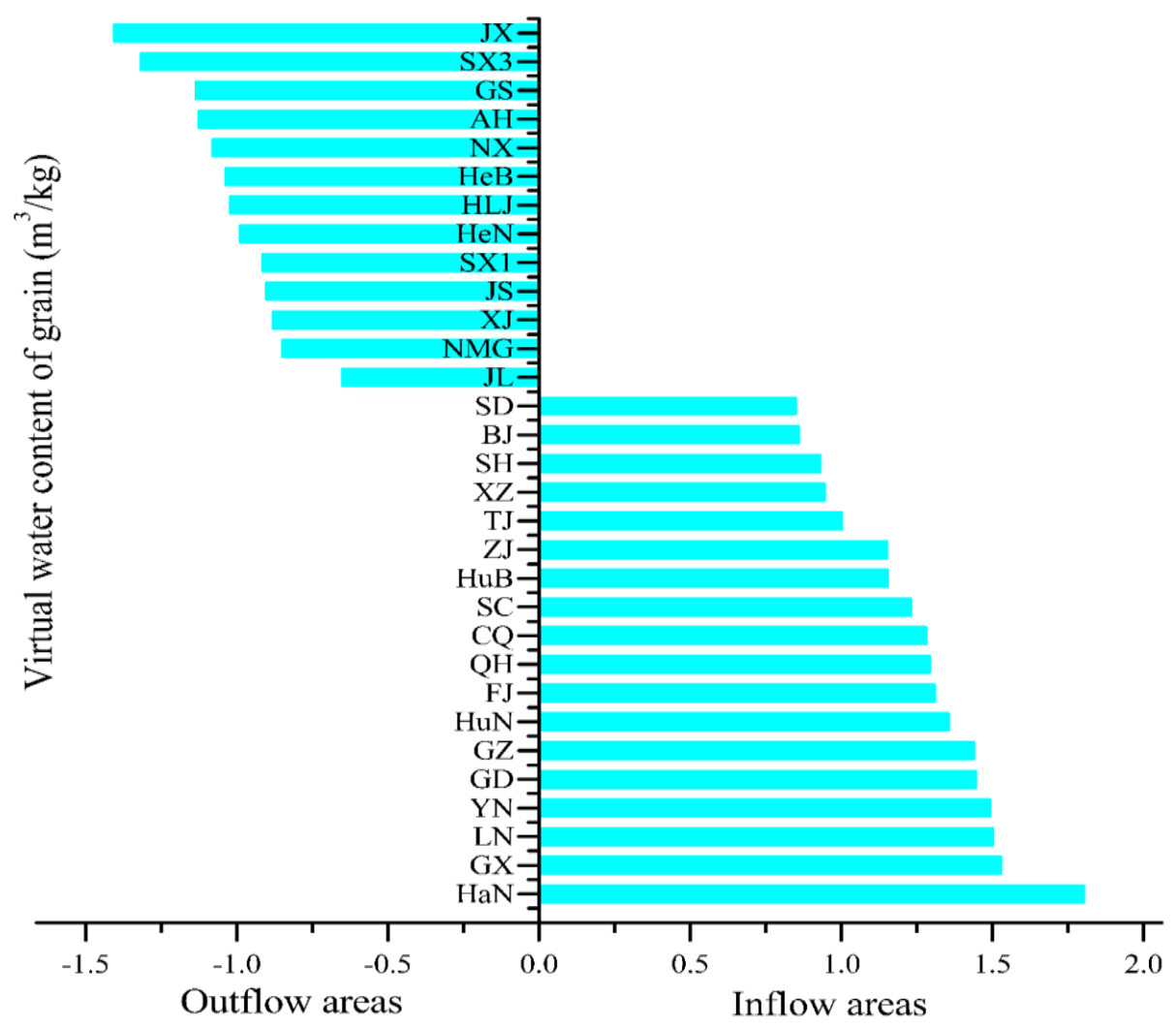

\section{Figure. 3 Virtual water content of grain in different regions}

Notes: The value of the virtual water content is not affected by positive and negative symbols; rather, positive values represent inflow areas and negative values represent outflow areas.

Table 3 Resource benefit in China's interprovincial grain trade

\begin{tabular}{|c|c|c|c|c|c|c|c|c|c|c|c|c|c|c|c|c|c|c|c|}
\hline & \multicolumn{19}{|c|}{ Inflow areas $\left(10^{9} \mathrm{~m}^{3}\right)$} \\
\hline & $\begin{array}{l}\text { Zone } \\
\text { Two }\end{array}$ & $\mathrm{BJ}$ & $\mathrm{TJ}$ & LN & $\mathrm{SH}$ & $\mathrm{ZJ}$ & FJ & SD & $\mathrm{HuB}$ & $\mathrm{HuN}$ & GD & GX & $\mathrm{HaN}$ & CQ & $\mathrm{SC}$ GZ & YN & $\mathrm{XZ}$ & QH & Total \\
\hline & $\mathrm{HeB}$ & & & & & & & & & & & & & & -0.1 & & & & -0.1 \\
\hline & SX1 & 0.2 & & & & & & & & & & & & & & & & & 0.2 \\
\hline & NMG & & & & & & & & & & -7.5 & & & -0.5 & & -1.0 & & & -8.9 \\
\hline & $\mathrm{JL}$ & -0.1 & & & -0.7 & & & & -1.2 & & & -7.2 & & & & & -0.1 & & -9.4 \\
\hline & HLJ & & & -1.6 & & -1.1 & & & & & -2.7 & & -1.9 & & -0.4 & & & & -7.6 \\
\hline outflo & JS & & -0.2 & & & & & & & & & & & & & & & & -0.2 \\
\hline $\mathrm{w}$ & $\mathrm{AH}$ & & & & & & & & & & & & & & -0.8 & & & & -0.8 \\
\hline areas & JX & & & & & & & & & & & & & 0.1 & & & & & 0.1 \\
\hline & $\mathrm{HeN}$ & & & & & & -2.0 & & & -0.8 & & & -0.2 & & & & & & -3.1 \\
\hline & SX3 & & & & & & 0.01 & & & & & & & & & & & & 0.01 \\
\hline & GS & & & -0.7 & & & & & & & & & & & -0.2 & & & & -0.9 \\
\hline & NX & & 0.03 & -0.3 & & & & & & & & & & & & & & & -0.3 \\
\hline & $\mathrm{XJ}$ & & & & & & & 0.2 & & & -0.2 & & & & & & & -0.2 & -0.3 \\
\hline & Total & 0.03 & -0.2 & -2.7 & -0.7 & -1.1 & -2.0 & 0.2 & -1.2 & -0.8 & -10.5 & -7.2 & -2.1 & -0.4 & $-1.1-0.4$ & -1.0 & -0.1 & -0.2 & -31.4 \\
\hline
\end{tabular}

Notes: Negative numbers represent water savings, and positive numbers represent water inefficiency.

The water resources saved by virtual water come from the three outflow areas of Jilin, Inner Mongolia and Heilongjiang, which represent $81.7 \%$ of the total savings of water resources in the 
outflow areas (Figure. 4a). The water resources saved from the three inflow regions of Guangxi, Guangdong and Liaoning account for $64.3 \%$ of the total savings of water resources in the inflow areas (Figure. 4b). As shown in Table 3, an interesting phenomenon is revealed. As far as the volume of water resources savings is concerned, the flow from Inner Mongolia to Guangdong is first, at up to $7.5 \times 10^{9} \mathrm{~m}^{3}$, followed by Jilin to Guangxi $\left(7.2 \times 10^{9} \mathrm{~m}^{3}\right)$ and Heilongjiang to Guangdong and Liaoning (up to $4.3 \times 10^{9} \mathrm{~m}^{3}$ ).
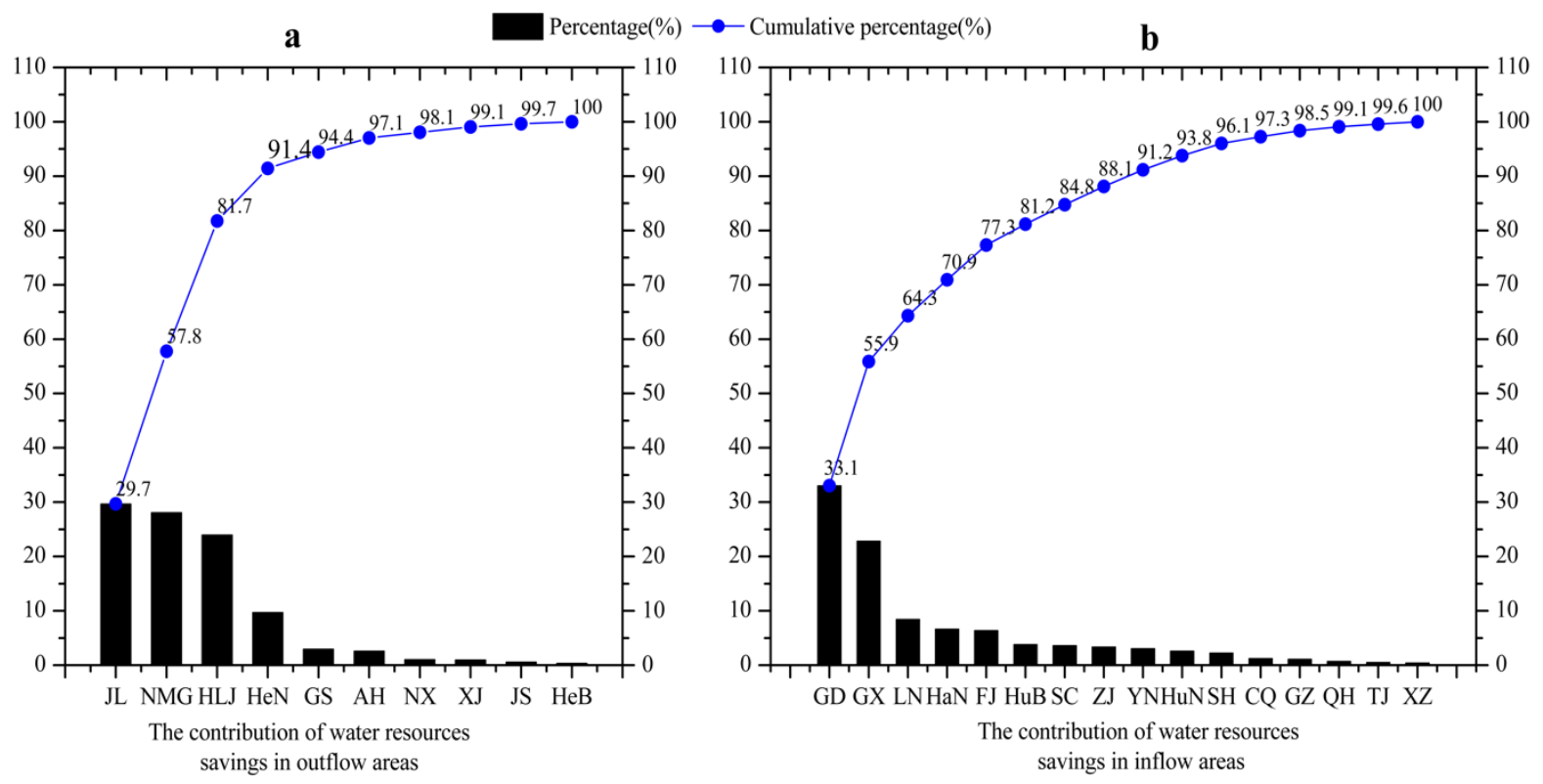

Figure. 4 The distribution of water resources savings in outflow/inflow areas

\section{(2) Economic benefit: increasing or decreasing}

The economic benefit of virtual water flow in China's interprovincial grain trade is increasing. The results show that the industrial added value is $6.4 \times 10^{12}$ yuan (Table 4 ).

Table 4 The change of industrial added value of the virtual water flow of China's interprovincial grain trade

Inflow areas $\left(10^{12}\right.$ yuan)

\begin{tabular}{lllllllllllllllll}
\hline Zone & BJ & TJ & LN & SH & ZJ & FJ & SD & HuB HuN GD & GX & HaN CQ & SC & GZ & YN & XZ & QH & Total
\end{tabular} 


\begin{tabular}{|c|c|c|c|c|c|c|c|c|c|c|c|c|c|c|c|}
\hline \multirow{14}{*}{$\begin{array}{l} \\
\text { Outflow } \\
\text { areas }\end{array}$} & $\mathrm{HeB}$ & & & & & & & & & & \multicolumn{4}{|c|}{0.2} & 0.2 \\
\hline & SX1 -0.7 & & & & & & & & & & & & & & -0.7 \\
\hline & NMG & & & & & & & & & 1.4 & 0.2 & & 0.4 & & 2.0 \\
\hline & $\begin{array}{ll}\text { JL } & -0.2\end{array}$ & & & 0.1 & & & & 0.2 & & & -0.03 & & & 0.1 & 0.2 \\
\hline & HLJ & & -1.4 & & -1.8 & & & & & -1.0 & -0.1 & & -0.02 & & -4.3 \\
\hline & JS & -1.2 & & & & & & & & & & & & & -1.2 \\
\hline & $\mathrm{AH}$ & & & & & & & & & & & -0.3 & & & -0.3 \\
\hline & $J X$ & & & & & & & & & & -0.0 & & & & -0.04 \\
\hline & $\mathrm{HeN}$ & & & & & 1.1 & & & 0.5 & & 0.1 & & & & 1.7 \\
\hline & SX3 & & & & & 0.9 & & & & & & & & & 0.9 \\
\hline & GS & & -0.9 & & & & & & & & & -0.2 & & & -1.1 \\
\hline & NX & -0.4 & -0.3 & & & & & & & & & & & & -0.7 \\
\hline & $\mathrm{XJ}$ & & & & & & -2.9 & & & -0.01 & & & & & $-0.02-2.9$ \\
\hline & Total -0.9 & -1.6 & -2.6 & 0.1 & -1.8 & 2.0 & -2.9 & 0.2 & 0.5 & 0.4 & $-0.03-0.030 .2$ & -0.3 & -0.020 .4 & 0.1 & $-0.02-6.4$ \\
\hline
\end{tabular}

Notes: Negative numbers indicate an increase in economic benefit; positive numbers indicate a decrease in economic benefit.
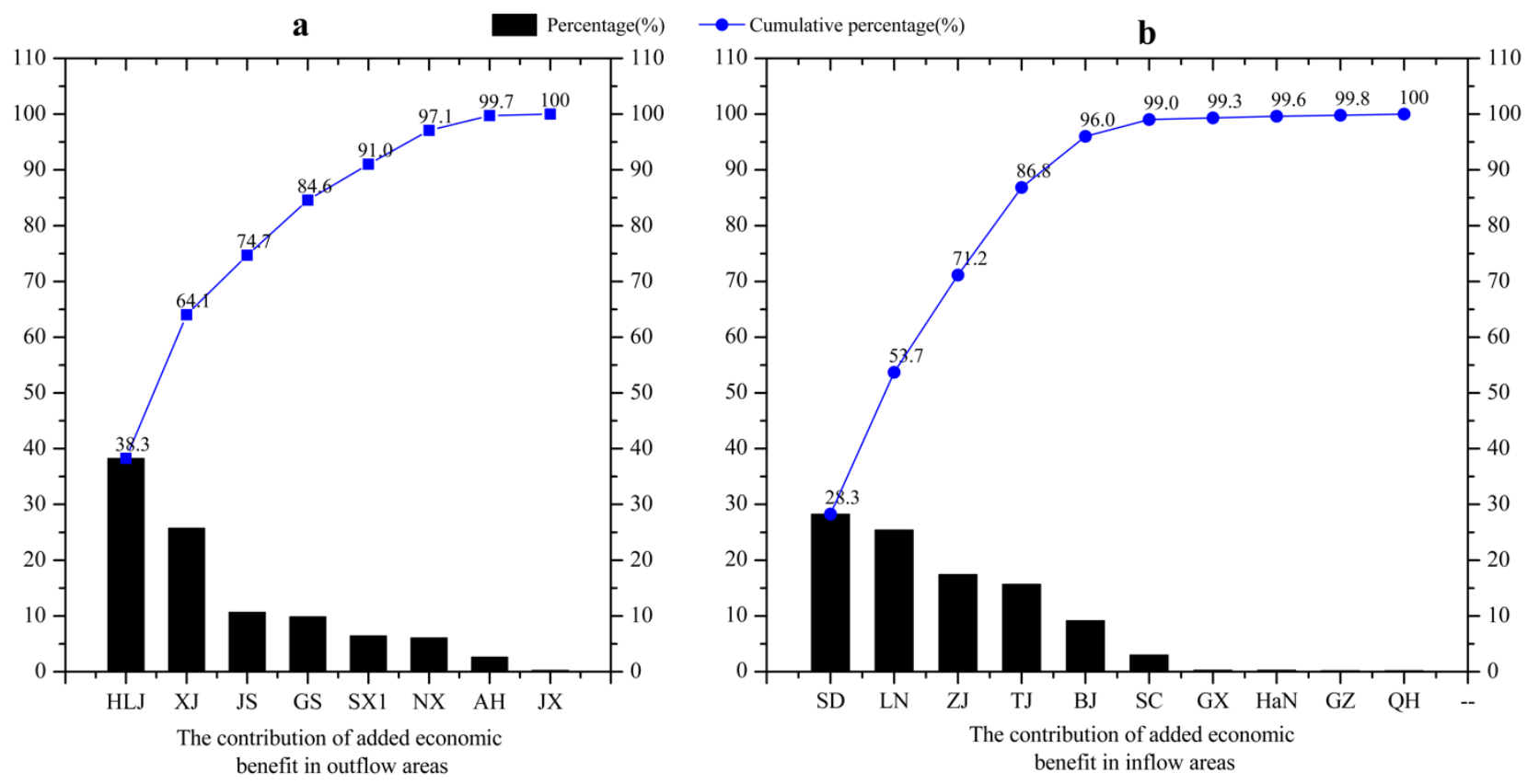

Figure. 5 The contribution of added economic benefit in outflow/inflow areas

As far as added economic benefit is concerned, a novel characteristic is found in that the outflow and inflow are fully matched. The added economic benefit caused by the virtual water from the four outflow areas of Heilongjiang, Xinjiang, Jiangsu and Gansu is $84.6 \%$ of the total added economic benefit in outflow areas (Figure. 5a). The added economic benefit of the four inflow regions of Shandong, Liaoning, Zhejiang and Tianjin is $86.8 \%$ of the total added economic benefit in inflow areas (Figure. 5b). Table 4 shows that the virtual water of Heilongjiang flows to multiple regions, of which the maximum added economic benefit is to Zhejiang. The virtual water of Xinjiang flows to multiple regions, of which the maximum added economic benefit is to Shandong; the virtual water of Jiangsu 
flows to multiple regions, of which the maximum added economic benefit is to Tianjin. The virtual water from Gansu to Liaoning causes the maximum added economic benefit during multiple virtual flows of Gansu.

\section{(3) Environmental benefit}

The green water occupation index of the crops of each region is calculated by Equation (5), and the results are shown in Figure. 6.

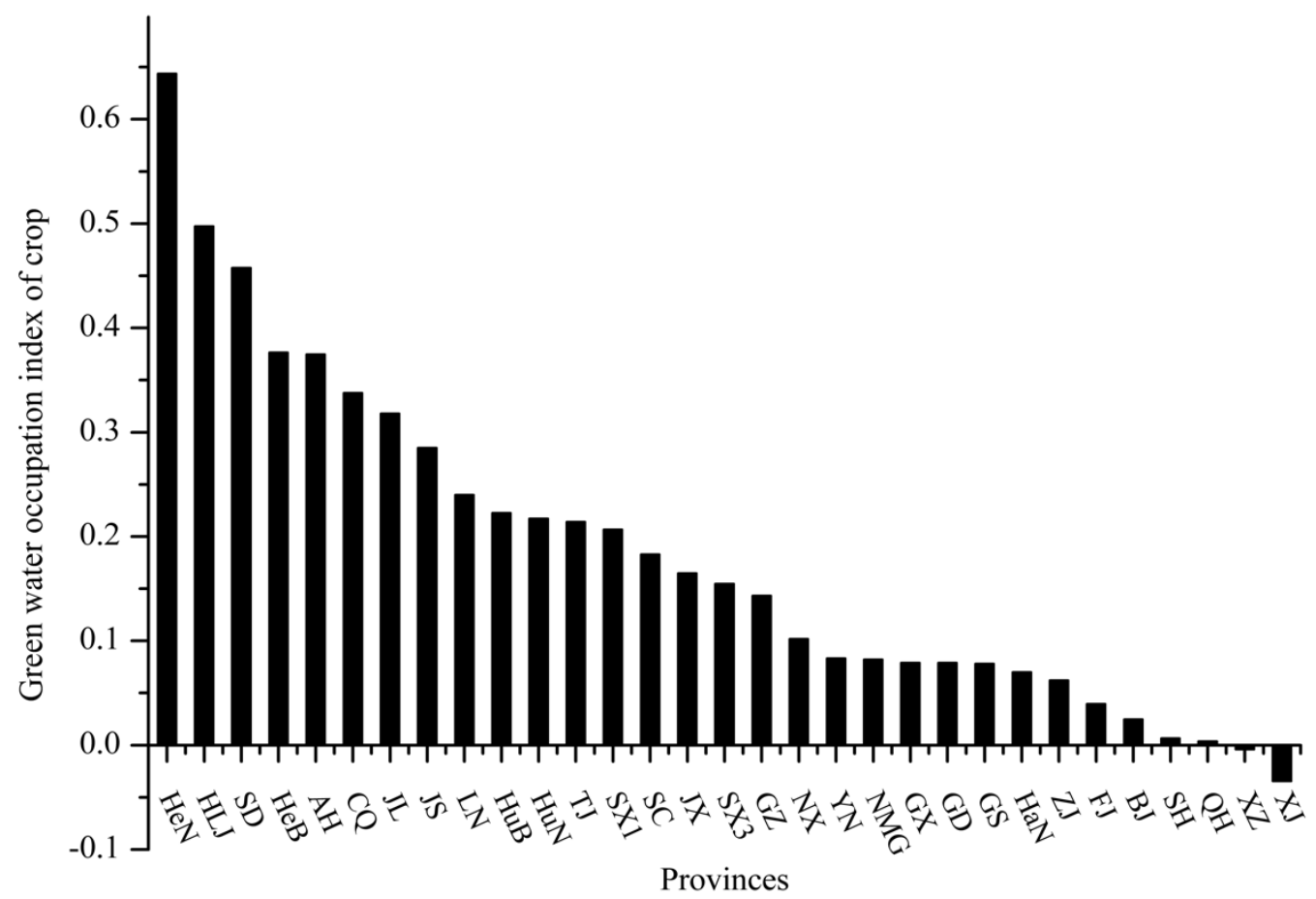

Figure. 6 Green water occupation index of crops in different regions

The top five listed regions with regard to the green water occupation index of crops are Henan, Heilongjiang, Shandong, Hebei and Anhui, and their index values are 64.4\%, 49.8\%, 45.8\%, 37.6\% and $37.5 \%$, respectively. The proportion of green water consumed by crop growth in these areas accounts for a large proportion of the total green water. It is shown from the green water resources that the water resources required by terrestrial natural ecosystems is misappropriated, which threatens the terrestrial ecosystem health to a certain extent. The last five listed regions with regard to the green water occupation index of crops are Xinjiang, Tibet, Qinghai, Shanghai and Beijing, while the proportion of green water consumed by crop growth in these areas is low. The regions with a high 
green water occupation index are virtual water outflow areas as well as areas with a shortage of water for daily living and crop production. These results show that the export of virtual water in these regions to other areas not only is harmful to the local agro-ecosystems but also exacerbates the threats to the local terrestrial natural ecosystem and socioeconomic development.

\section{Conclusions and implications}

A linear optimization model is proposed to estimate the flow pattern of interprovincial grain trade in China taking 2015 as an example, the comprehensive benefits caused by virtual water flow in grain trade are analyzed from both outflow and inflow comparative perspectives, the results shown that virtual water trade between regions can relieve the pressure on limited water recourses, contribute to improving the water use efficiency at the national level, promote the economic value of water and maintain ecological security. Several specific conclusions and policy implications are presented below.

\subsection{Conclusions}

(1) Virtual water flow in China's interprovincial grain trade should be given enough attention, water resources can be greatly saved by optimizing the pattern of virtual water flow. The total amount of virtual water flow in China's interprovincial grain trade is $79.2 \times 10^{9} \mathrm{~m}^{3}$, accounting for $20.5 \%$ of the total agricultural water consumption, the $31.4 \times 10^{9} \mathrm{~m}^{3}$ of water resource is saved by the proposed pattern of virtual water flow in China's interprovincial grain trade, which accounts for $39.7 \%$ of the total amount of virtual water flow. The virtual water flow shows the characteristics of water transfer from water-scarce regions to water-abundant regions, which exacerbates the water resources shortage in the northern region to some extent.

(2) The overall economic benefit of saving water resources via optimizing the pattern of virtual water flow is huge and can be explained by the result of the virtual water trade from high water productivity regions to low water productivity regions. The economic benefit increased by $6.4 \times 10^{12}$ yuan in 2015, which indicates that the virtual water in the grain trade flows from high value-added industrial production areas to low value-added areas, resulting in higher economic value, such as the 
$1.8 \times 10^{12}$ yuan increase in virtual water trade from Heilongjiang to Zhejiang. A reduction of economic benefit occurs when the virtual water flows in the opposite direction. The calculation of economic benefit takes the high value of virtual water use into consideration, contributing to the more efficient allocation of water. Attention should be paid to this factor because it can be a means to improve water management. In terms of the economic benefit reduction, the virtual water flow of certain provinces (including Inner Mongolia and Henan) goes against the principle of more efficient water allocation. The outflow areas have intensively developed grain production due to the arable land advantage; conversely, the inflow areas have concentrated on economic development.

(3) From the perspective of environmental benefit, the areas with a high green water occupation index of crops are mainly located in the Huang-Huai-Hai region, and the proportion of green water consumed in grain production is large, which occupies the green water resources required by natural terrestrial ecosystems. In addition, these regions with water shortage problems are also virtual water outflow areas, and the export of virtual water to other areas not only is harmful to the local agroecosystem but also exacerbates impacts on the local terrestrial ecosystems and socioeconomic development.

\subsection{Policy implications}

(1) Due to the difficulty of fundamentally changing the flow pattern of grain trade among provinces in China, some economic means should be taken, such as improving grains and water pricing system by taking water scarcity and disparity in different regions. The virtual water flow through grain trade is from the drier North to the wetter South, which is a paradox in China. Similar paradoxes have occurred in the global virtual water trade (Kumar and Singh, 2005; Ansink, 2010; Reimer, 2012; Guan and Hubacek, 2007) and many studies have explained the phenomenon, the reason is that arable land has played a more decisive role in grain production than water. Thus, the virtual water flow in interregional grain trade is from "land-rich, water-poor regions" to "land-poor, water-rich" regions. So the water price should reflect water scarcity and the value of water in grain production and consider 
provincial disparities in water scarcity. A reasonable price can prevent the overload of water-intensive production in arid areas.

(2) Some measures to improve water productivity and explore regional compensation mechanisms are strongly advised to take. Water inefficiency in virtual water flow through grain trade reveals low water productivity in many provinces, nearly half of the outflow areas. Improving water productivity by water-saving technology and water-saving production practices is a basic and important means to solve water shortages. In addition, the allocation of virtual water can be more efficient when virtual water is used for economic development in water-scare regions themselves, such as Inner Mongolia, Henan and Shaanxi, rather than flowing to other regions. However, the virtual water flows from Inner Mongolia to Guangdong, from Henan to Fujian, and from Shaanxi to Fujian result in a reduction of economic benefit. On the one hand, these outflow regions meet the grain demand in grain-deficit provinces, playing an important role in national food security. On the other hand, the development of these regions cannot be ignored. It is imperative to explore regional compensation mechanisms to realize regional balance and sustainable development. Compensation methods should be developed and deployed, including actual water compensation, virtual water compensation, and economic compensation.

(3) Improving green water conservation capacity. Green water is water that has infiltrated into the unsaturated soil layer by precipitation for the growth of plants. It is advisable to improve green water conservation capacity to protect terrestrial ecosystems. Specific measures can include tree planting, grassland protection, river and lake protection, and so on, especially in the Huang-Huai-Hai region. This region, which has a high crop green water occupation index, directs a substantial amount of available green water to the local agricultural ecosystem. Meanwhile, massive output of virtual water will aggravate the destruction of terrestrial ecosystems.

\section{Acknowledgements}

This study was supported by the National Key Research and Development Program of China (No. 
2017YFC0403504) and the National Science Foundation of China (Nos. 51479119 and 51579064) and the Fundamental Research Funds for the Central Universities (No. 2018B25014). We express our thanks for the work of the Data Assimilation and Modeling Center for Tibetan Multi-spheres, Institute of Tibetan Plateau Research, Chinese Academy of Sciences, for developing the China Meteorological Forcing Dataset we adopted. The authors thank the editor and the anonymous reviewers for their comments, which helped improve the quality of the paper.

\section{Appendix A}

Table A1 Introduction to China's Provinces (excluding Hong Kong, Macao and Taiwan)

\begin{tabular}{|c|l|l|l|l|l|}
\hline Number & Abbreviation & Full name & Number & Abbreviation & Full name \\
\hline 1 & BJ & Beijing & 17 & HuB & Hubei \\
\hline 2 & TJ & Tianjin & 18 & HuN & Hunan \\
\hline 3 & HeB & HeBei & 19 & GD & Guangdong \\
\hline 4 & SX1 & Shanxi & 20 & GX & Guangxi \\
\hline 5 & NMG & Inner Mongolia & 21 & HaN & Hainan \\
\hline 6 & LN & Liaoning & 22 & CQ & Chongqing \\
\hline 7 & JL & Jilin & 23 & SC & Sichuan \\
\hline 8 & HLJ & Heilongjiang & 24 & GZ & Guizhou \\
\hline 9 & SH & Shanghai & 25 & YN & Yunnan \\
\hline 10 & JS & Jiangsu & 26 & XZ & Tibet \\
\hline 11 & ZJ & Zhejiang & 27 & SX3 & Shaanxi \\
\hline 12 & AH & Anhui & 28 & GS & Gansu \\
\hline 13 & FJ & Fujian & 29 & QH & Qinghai \\
\hline 14 & JX & Jiangxi & 30 & NX & Ningxia \\
\hline 15 & SD & Shandong & 31 & XJ & Xinjiang \\
\hline 16 & HeN & Henan & & & \\
\hline
\end{tabular}




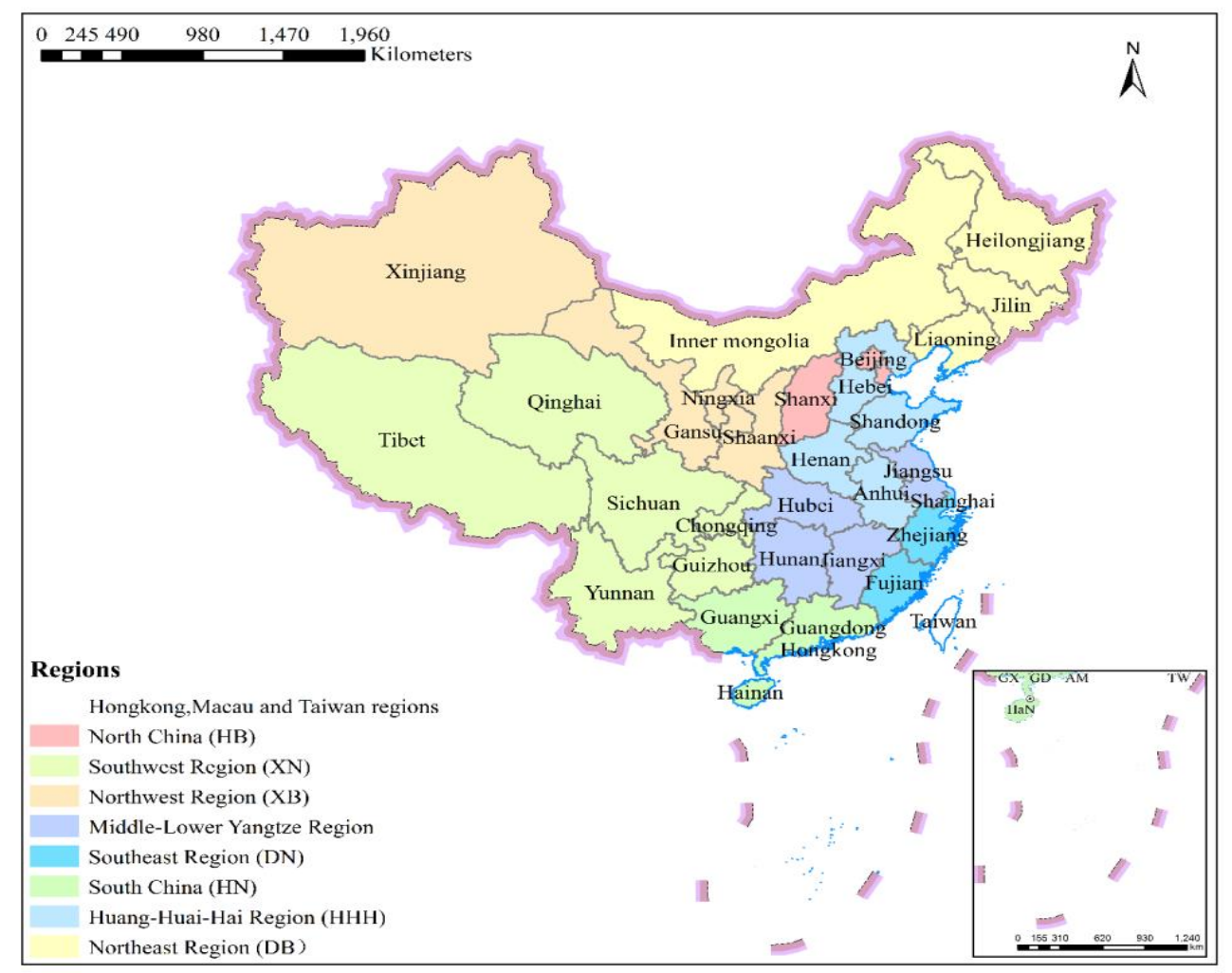

Fig. A1 Distribution map of Chinese provinces and regions

\section{References}

Allan, J.A., 1993. Fortunately there are substitutes for water otherwise our hydro-political futures would be impossible. Priorities water Resour. Alloc. Manag. 13.

Allan, J.A., 1998. Virtual water: A strategic resource global solutions to regional deficits. Groundwater $36,545-546$.

Allan, J.A., 2003. Useful Concept or Misleading Metaphor? Virtual Water : A Definition. Water Int. 28, 4-11. https://doi.org/10.1080/02508060.2003.9724812.

Allen, R.G., Pereira, L.S., Raes, D., Smith, M., Ab, W., 1998. Crop evapotranspiration - Guidelines for computing reference crop evapotranspiration, FAO, Rome. 1-15. https://doi.org/10.1016/j.eja.2010.12.001.

Ansink, E., 2010. Refuting two claims about virtual water trade. Ecol. Econ. 69, 2027-2032. 
Ben, P., Wu, S., Li, X., Zhou, S., 2016. China's inter-provincial grain trade and its virtual cultivated land flow simulation. Geogr. Res. 8, 5.

Cao, X. C., Wu, P.T., Wang, Y. B., Zhao, X. N., Li, S., 2011. Application of virtual water trade theory in inter-regional grain allocation and transportation in China. African J. Biotechnol. 10, 1846318471.

Chapagain, A.K., Hoekstra, A.Y., Savenije, H.H.G., 2005. Saving water through global trade, Value of Water Research Report Series No. 17, UNESCO-IHE,Delft, the Netherlands.

Chapagain, A.K., Hoekstra, A.Y., Savenije, H.H.G., 2006. Water saving through international trade of agricultural products. Hydrol. Earth Syst. Sci. 10, 455-468. https://doi.org/10.5194/hess-10-4552006.

Chen, G.Q., Li, J.S., 2015. Virtual water assessment for Macao, China: highlighting the role of external trade. J. Clean. Prod. 93, 308-317.

Chen, W., Wu, S., Lei, Y., Li, S., 2018. Virtual water export and import in china's foreign trade: A quantification using input-output tables of China from 2000 to 2012. Resour.Conserv.Recycl. 132, 278-290. https://doi.org/10.1016/j.resconrec.2017.02.017.

Cheng, Y. F. 2004. Food supply demand and projection in China. China Agriculture Press. Beijing.(in Chinese)

China Food Industry Association, 2015. China Food Industry Yearbook 2015. Zhonghua Book Company Publishing House. Beijing.(in Chinese)

Dalin, C., Qiu, H., Hanasaki, N., Mauzerall, D.L., Rodriguez-Iturbe, I., 2015. Balancing water resource conservation and food security in China. Proc. Natl. Acad. Sci. 112, 4588-4593.

Elfadel, M. , Maroun, R., 2003. The concept of "virtual water" and its applicability in Lebanon. At International Expert Meeting on Virtual Water Trade International Expert Meeting on Virtual Water Trade. 12 -13.

Ercin, A.E., Hoekstra, A.Y., 2014. Water footprint scenarios for 2050: A global analysis. Environ. Int. 
$64,71-82$.

Guan, D., Hubacek, K., 2007. Assessment of regional trade and virtual water flows in China. Ecol. Econ. 61, 159-170. https://doi.org/10.1016/j.ecolecon.2006.02.022.

Hoekstra, A.Y., 2003. Virtual water: An introduction, in: Virtual Water Trade: Proceedings of the International Expert Meeting on Virtual Water Trade. Value of Water Research Report Series No 11. IHE Delft, pp. 13-23.

Hoekstra, A.Y., Hung, P.Q., 2005. Globalisation of water resources: International virtual water flows in relation to crop trade. Glob. Environ. Chang. 15, 45-56. https://doi.org/10.1016/j.gloenvcha.2004.06.004.

Hu, S., Wang, Z., Wang, Y., Zhang, L., 2010. Total control-based unified allocation model for allowable basin water withdrawal and sewage discharge. Sci. China Technol. Sci. 53. https://doi.org/10.1007/s11431-010-0155-8.

Jiang, S., Wang, J., Zhao, Y., Shang, Y., Gao, X., Li, H., Wang, Q., Zhu, Y., 2017. Sustainability of water resources for agriculture considering grain production, trade and consumption in China from 2004 to 2013. J. Clean. Prod. 149.

Jiang, Y., Cai, W., Du, P., Pan, W., Wang, C., 2015. Virtual water in interprovincial trade with implications for China's water policy. J. Clean. Prod. 87, 655-665. https://doi.org/10.1016/j.jclepro.2014.10.074.

Jiao, X.Q., He, G., Cui, Z.L., Shen, J.B., Zhang, F.S., 2018. Agri-environment policy for grain production in China: Toward sustainable intensification. China Agric. Econ. Rev. https://doi.org/10.1108/CAER-10-2017-0201

Jing, M.A., Wang, D.X., Hoekstra, A.Y., Xia, H.X., 2006. Application of the virtual water trade to China's grain security. Adv. Water Sci. 17, 102-107.

Kang, S., Hao, X., Du, T., Tong, L., Su, X., Lu, H., Li, X., Huo, Z., Li, S., Ding, R., 2017. Improving agricultural water productivity to ensure food security in China under changing environment: 
From research to practice. Agric. Water Manag. https://doi.org/10.1016/j.agwat.2016.05.007.

Konar, M., Dalin, C., Suweis, S., Hanasaki, N., Rinaldo, A., Rodriguez-Iturbe, I., 2011. Water for food: The global virtual water trade network. Water Resour. Res. 47. https://doi.org/10.1029/2010WR010307.

Kumar, M.D., Singh, O.P., 2005. Virtual water in global food and water policy making: Is there a need for rethinking? Water Resources Management. https://doi.org/10.1007/s11269-005-3278-0.

Liu, B., Feng, Z., Yao, Z.,2006. Theory, Method and Progress on Virtual Water Research. Resour Sci.28, 120-127. (in Chinese)

Ma, J., Hoekstra, A.Y., Wang, H., Chapagain, A.K., Wang, D., 2006. Virtual versus real water transfers within China. Philos. Trans. R. Soc. B Biol. Sci. 361, 835-842.

Ministry of Agriculture People's Republic of China, 2016. China Agriculture Yearbook 2016. China Agriculture Press, Beijing. (in Chinese)

Ministry of Water Resources People's Republic of China, 2015. China Water Resources Bulletin 2015. China Water \& Power Press, Beijing. (in Chinese)

Miller, R.E., Blair, P.D., 2009. Input-Output Analysis: Foundations and Extensions,second ed. Cambridge University Press http://www.cambridge.org/millerandblair.

National Bureau of Statistics, 2016. China Statistical Yearbook 2016. China Statistical Publishing House, Beijing.(in Chinese)

Novo, P., Garrido, A., Varela-Ortega, C., 2009. Are virtual water "flows" in Spanish grain trade consistent with relative water scarcity? Ecol. Econ. 68, 1454-1464.

Piao, S., Ciais, P., Huang, Y., Shen, Z., Peng, S., Li, J., Zhou, L., Liu, H., Ma, Y., Ding, Y., Friedlingstein, P., Liu, C., Tan, K., Yu, Y., Zhang, T., Fang, J., 2010. The impacts of climate change on water resources and agriculture in China. Nature. https://doi.org/10.1038/nature09364

Reimer, J.J., 2012. On the economics of virtual water trade. Ecol. Econ. 75, 135-139. 
Sun, C.Z., Zhang L., 2009. Evolution of China's agricultural products' virtual water-cultivated land resources from the perspective of regional spatial-temporal difference. Resour Sci. 31, 84-93.(in Chinese)

Sun, C.Z.,Chen, L.X., Liu Y.Y, 2010.Spatial and temporal variation of crop green water occupancy index in China. Adv. Water Sci. 21, 637-643.(in Chinese)

Tao, M.A., Chen, J.K., 2006. The Role of Virtual Water Trade in Efforts to Resolve China and Global Water Crisis. Ecol. Econ.

Wang, L.,Gan, H., Gu, J.F., Lu, Y.Z., 2010. Study on characteristics of economic value of water in Haihe River basin. Hydrol. Eng. 41,646-652.(in Chinese)

Wang, Y., Xiao, H.L., Lu, M.F., 2009. Analysis of water consumption using a regional input-output model: model development and application to Zhangye City, Northwestern China. J. Arid Environ. 73, 894-900.

Wang, Z., Huang, K., Yang, S., Yu, Y., 2013. An input-output approach to evaluate the water footprint and virtual water trade of Beijing, China. J. Clean. Prod. 42, 172-179.

Wang, Z., Zhang, L., Zhang, Q., Wei, Y.-M., Wang, J.-W., Ding, X., Mi, Z., 2019. Optimization of virtual water flow via grain trade within China. Ecol. Indic. 97, 25-34. https://doi.org/10.1016/j.ecolind.2018.09.053.

Weidmann, T., Lenzen, M., Barratt, P. J., \& Turner, K., 2007. Examining the global impact of regional consumption activities - part 2: review of input-output models for the assessment of environmental impacts embodied in trade. Ecological Economics,61(1), 15-26.

Yang, L., 2009. Analysis of grain supply and demand balance in China. Shandong University of Technology, Zibo city.(in Chinese)

Zeitoun, M., Allan, J.A. (Tony., Mohieldeen, Y., 2010. Virtual water “flows" of the Nile Basin, 19982004: A first approximation and implications for water security. Glob. Environ. Chang. 20, 229242. https://doi.org/10.1016/j.gloenvcha.2009.11.003. 
Zhang, C., Anadon, L.D., 2014. A multi-regional input-output analysis of domestic virtual water trade and provincial water footprint in China. Ecol. Econ. 100, 159-172. https://doi.org/10.1016/j.ecolecon.2014.02.006.

Zhang, Y., Zhang, J., Wang, C., Cao, J., Liu, Z., Wang, L., 2017. China and Trans-Pacific Partnership Agreement countries: Estimation of the virtual water trade of agricultural products. J. Clean. Prod. 140, 1493-1503. https://doi.org/10.1016/j.jclepro.2016.10.001.

Zhang, Z., Yang, H., Shi, M., 2011. Analyses of water footprint of Beijing in an interregional inputoutput framework. Ecol. Econ. 70, 2494-2502.

Zhang, Z.Y., Yang, H., Shi, M.J., Zehnder, A.J.B., Abbaspour, K.C., 2011. Analyses of impacts of China's international trade on its water resources and uses. Hydrol. Earth Syst. Sci. 15, 28712880.

Zhuo, L., Mekonnen, M.M., Hoekstra, A.Y., 2016. Water footprint and virtual water trade of China past and future. Value water Res. Rep. Ser. No. 69, UNESCO-IHE, Delft, the Netherlands. 